\title{
Hyperintense signal in pyramidal tract neurons in postoperative brain tumor: wallerian degeneration or neoplastic dissemination?
}

Sinal hiperintenso no trato piramidal no pós-operatório de tumor cerebral: degeneração walleriana ou disseminação neoplásica?

Ricardo Mendes Rogerio', José Luiz Pedroso², Acary Souza Bulle Oliveira², Lázaro Luis Faria do Amaral

A 46-year-old man presented with behavioral changes and partial seizures over 20 days. Neurological examination showed mental confusion. Brain MRI showed a ringshaped lesion in the left frontal lobe (A and B). Surgery was performed $(\mathrm{C})$ and pathology confirmed glioblastoma multiforme. The patient underwent radiotherapy and chemotherapy.
A control MRI (eight months later) showed hyperintense signal in the left pontine base (D and E), suggesting wallerian degeneration or neoplastic dissemination. Four months later, there was a marked increase in lesion size, confirming that the hyperintense signal in the pyramidal tract was neoplastic dissemination (F). Follow-up imaging may differentiate wallerian degeneration from tumor spread ${ }^{1,2}$.

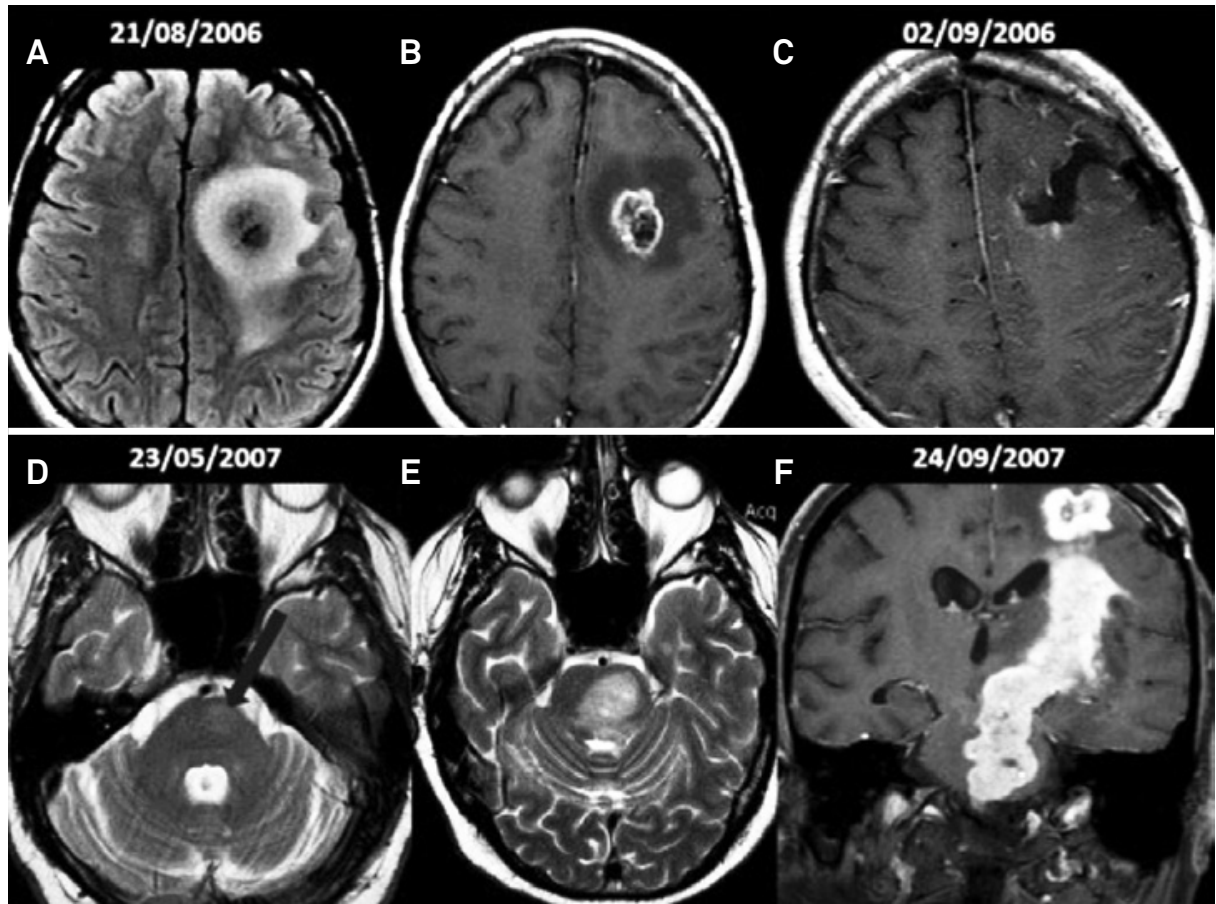

Figure. (A) axial FLAIR; (B) axial T1-weighted brain MRI disclosing an infiltrative lesion, suggesting a brain tumor. Note necrotic center and gadolinium enhancement, surrounded by vasogenic edema in the upper and middle frontal gyri of the left cerebral hemisphere; (C) axial T1-weighted brain MRI demonstrating postoperative imaging; (D) axial T2-weighted brain MRI showing hyperintense signal in the left portion of the paramedian pontine base, in the topography of the pyramidal tract; (E) axial T2-weighted brain MRI; (F) coronal T1-weighted brain MRI disclosing an infiltrative and neoplastic lesion, with a marked hyperintense signal throughout the left pyramidal tract, from the corona radiata to the pontine base.

\footnotetext{
1Department of Neuroradiology, Hospital Beneficência Portuguesa de São Paulo, São Paulo SP, Brazil;

2Department of Neurology, Universidade Federal de São Paulo, São Paulo SP, Brazil.

Correspondence: Ricardo Mendes Rogerio; Rua Martiniano de Carvalho 1049; 01321-001 São Paulo SP - Brasil; E-mail: ricardomendesrogerio@gmail.com Conflict of interest: There are no conflicts of interest to declare.

Received 19 May 2013; Received in final form 21 May 2013; Accepted 28 May 2013.
} 


\section{References}

1. Goebell E, Fiehler J, Ding XQ, et al. Disarrangement of fiber tracts and decline of neuronal density correlate in glioma patients - a combined diffusion tensor imaging and 1 H-MR spectroscopy study. AJNR Am J Neuroradiol 2006;27:1426-1431.
2. Rees JH, Smirniotopoulos JG, Jones RV, Wong K. Glioblastoma multiforme: radiologic-pathologic correlation. Radiographics 1996;16:1413-1438. 